\title{
Challenges in Harmonizing Energy and Nutrient Recommendations in Europe
}

\author{
Mirjana Pavlovic ${ }^{a}$ Ann Prentice ${ }^{b}$ Inga Thorsdottir ${ }^{c}$ Gunther Wolfram ${ }^{d}$ \\ Francesco Branca ${ }^{\text {A }}$ \\ ${ }^{a}$ Department of Nutrition and Metabolism, Institute for Medical Research, University of Belgrade, Belgrade, Serbia; \\ ${ }^{b}$ Medical Research Council, Human Nutrition Research, Elsie Widdowson Laboratory, Cambridge, UK; \\ 'Unit for Nutrition Research, Landspitali-University Hospital and Department of Food Science and Human Nutrition, \\ University of Iceland, Reykjavík, Iceland; ' Department Nutrition and Food Sciences, Technical University of Munich,

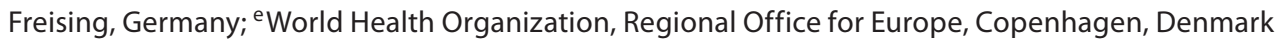

Key Words

Energy $\cdot$ Nutrient $\cdot$ Recommendations, dietary

\begin{abstract}
At the present time, there is considerable diversity in the dietary reference values and recommendations used across Europe, both in terms of terminology and guideline values. Harmonization of dietary reference values would be beneficial in simplifying nutritional policy, trade, and public understanding of diet and health issues. However, this is not a simple task because of the differences in methodological approaches adopted and the assumptions made. In addition, there are genuine differences in diet, lifestyle and geography that may necessitate retaining variation in some dietary reference values between European nations. The complexities of harmonization were discussed at a recent symposium held under the auspices of the Federation of European Nutrition Societies (FENS). This provided overviews of the different terminologies currently in use, of the variations in reference values for children and adolescents, and of the disparities between different groups of countries in Europe. The symposium hosted by FENS provided a forum to exchange views and to consider the steps that will be needed if harmonization is to be realized in the future. A summary of the presentations and conclusions is presented here.
\end{abstract}

Copyright $\odot 2007$ S. Karger AG, Basel

\section{KARGER}

Fax +41613061234 E-Mail karger@karger.ch www.karger.com
(C) 2007 S. Karger AG, Basel

0250-6807/07/0512-0108\$23.50/0

Accessible online at: www.karger.com/anm

\section{Introduction}

The need to establish guidelines on nutritional requirements for populations and groups has been on the agenda since the infancy of nutrition science. The concept of dietary recommendations goes back several centuries [1]. In the last century its importance was recognized early on by the newly formed United Nations (UN), and by 1949/50 both the Food and Agriculture Organization (FAO) and the World Health Organization (WHO) had convened groups of experts to evaluate existing evidence and provide advice to policy-makers on dietary intakes of nutrients [2]. Today the topic continues to receive at least as much attention as before, parallel to the increasing understanding of nutrient metabolism.

This article takes up some of the issues discussed at the Federation of European Nutrition Societies (FENS) symposium, 'Harmonization of the nutrient requirements', held September 22, 2005, in Durban. The workshop was linked to the 18th International Congress of Nutrition of the International Union of Nutrition Sciences. The agenda and the various presentations can be found on the FENS homepage [3].

The chair of the workshop (Francesco Branca) introduced the topic and pointed to the existing energy and nutrient reference values in different regions in Europe

Mirjana Pavlovic

Teslina Street 68/12

CS-24000 Subotica (Serbia)

Tel./Fax +381 24548 398, E-Mail mirjana.pavlovicmd@gmail.com 
and the differences between these recommendations. The topics presented were an overview of dietary reference values across Europe for children and adolescents (Ann Prentice), the Nordic nutrition reference values that integrated physical activity into the recommendations (Inga Thorsdottir), and the German, Austrian and Swiss $(\mathrm{DACH})$ reference values - a model for reference values in central Europe (Gunther Wolfram).

\section{Current Nutrient Recommendations in Europe: A Comparison}

\section{The Purpose of Dietary and Nutrient}

\section{Recommendations}

The aim of nutritional recommendations today is to provide guidelines for the nutrient composition of diets as a basis for good health and quality of life. The basis for setting such recommendations is the scientific evidence available for each individual nutrient. Definitions and terminology used today are diverse and have become more complex over the years; however, the basis for the terminology in different countries is similar. An individual's dietary requirement for nutrients depends on factors such as age, gender, genetic condition, level of physical activity, and health status, as well as absorption and utilization of nutrients. Dietary recommendations, now more generally termed 'reference values', are designed for populations or groups and represent the intakes considered sufficient to meet the requirements of the majority of healthy individuals (generally 97.5\%) of that population or group. Factors influencing the differences between the various international reference values are assumptions made about diet composition (e.g. effects on nutrient absorption, bioavailability), anthropometry (i.e. body mass, growth rate), definition of reference groups (especially age, boundaries and gender), health status, socioeconomic factors (e.g. occupation and income), climate, geography, ethnicity, culture and religion, specific risk groups (e.g. smokers, infants, very old people), and policies [4-13].

The Scientific Committee on Food of the EU [14] defined the following three reference levels.

Average requirement: The mean intake to meet the average physiological requirement.

Population reference intake: The intake that will meet the needs of nearly all healthy people in the population or group (the 97.5th percentile; mean $+2 \mathrm{SD}$ ).

Lowest threshold intake: The intake below which nearly all individuals in the population or group will be un- able to maintain metabolic integrity according to the criterion chosen (the 2.5th percentile; mean $-2 \mathrm{SD}$ ).

A somewhat different approach can be found in the $\mathrm{DACH}$ reference values which uses the following terminology $[9,10]$.

Recommendations: Average requirement increased by 2 SD assuming a normal distribution. Lacking a normal distribution of values, the average requirement can be increased by $20-30 \%$ (assuming a coefficient of variation of $10-15 \%)$.

Estimated values: If human requirements for a nutrient cannot yet be determined with desirable accuracy, estimated values are used. They are still experimentally supported and provide appropriate information for adequate and safe intake.

Guiding values: Aids for orientation, if some regulations of intake (lower limit for water, fluoride, dietary fiber and upper limit for fat, cholesterol, alcohol and table salt) are necessary for health reasons.

Here it is maintained that it is sufficient that reference values are met within a week. Nutrients should be ingested as regularly as possible and not in high doses, since the absorption rates of certain nutrients decrease with increasing intake [10].

In the terminology adopted by the UK, 'dietary reference values' are constructed around the 'estimated average requirement' [4]. The 'lower reference nutrient intake' is the value 2 SD below the estimated average requirement and the 'reference nutrient intake' (RNI) is the value $2 \mathrm{SD}$ above the estimated average requirement. The requirements of $97.5 \%$ of the population are likely to be greater than the lower RNI; likewise $97.5 \%$ of the population is likely to have requirements less than the RNI. Intakes at or above the RNI are considered adequate for almost everybody. The RNI is, therefore, equivalent to the 'population reference intake' used by the EU and to 'recommended daily allowance' (RDA) used in some other countries [2, 3, 9-11, 13].

In the Nordic Nutrient Recommendations (NNR) [7, $8]$, the term 'average requirement' is used to define the intake of a nutrient that represents the average requirement for a defined group of individuals. The term 'average requirement' is also used by the EU Scientific Committee on Food, while the Food and Nutrition Board of the National Academy of Science in the USA, developed jointly by American and Canadian scientists [14], and British dietary reference values use the term 'estimated average requirement'. In the NNR the term 'recommended intake' refers to 'the amount of a nutrient that according to present knowledge can meet the known require- 
ment and maintain good nutritional status among practically all healthy individuals'. This definition corresponds to definitions used by other expert committees, e.g. the UK RNI, the DACH recommendations and the EU Scientific Committee on Food population reference intake [2, 5-11].

Thus it is clear that there are differences in terminology within Europe. These disparities show a need for harmonization within Europe. This is important because terminology has implications for recommendations, and such recommendations are used for varied purposes in national and international planning and legislation. If the terminology is confusing, this can lead to confusing messages, and may have serious policy and health consequences. Therefore it would be wise for various expert committees established by the UN, EU and separate countries to embark on collaboration to standardize terminology and definitions.

\section{Dietary Reference Values for Children and}

Adolescents across Europe

As an example of the differences that exist and the difficulties that will be faced, in an activity to harmonize dietary reference values (DRVs) across Europe, a compilation of values for children aged 2-18 years has recently been published [5]. Information on DRVs current in September 2002 was obtained for 29 of the 31 countries in Europe. Tables were constructed to compare and contrast the DRVs for energy, macronutrients, vitamins, minerals and trace elements, separated by sex and year of age. Brief summaries were written for each dietary component to document the scientific basis for the values, including assumptions made, and to offer, where possible, an explanation for the differences between countries for each nutrient. This exercise demonstrated the wide disparities that currently exist within each sex/age group: up to 2 fold for macronutrients, 10 -fold for fiber, and 2- to 4-fold for vitamins, minerals and trace elements. Some of these differences can be ascribed to real physiological and environmental variations in different European regions. Examples include variations in DRVs for vitamin D that reflect assumptions made about the extent of endogenous synthesis in the skin due to sunshine exposure in each country, and in those for iron and zinc which reflect considerations about local diet composition and the efficiency of absorption of these minerals. However, the inconsistencies are mostly due to disparities in philosophy about the best methodological approach to use, the assumptions made, for example about growth patterns and the timing of puberty, and the way in which the various methodological approaches are applied. These issues will need to be resolved as a first step towards harmonization of DRVs across Europe.

\section{Comparison between the Nordic Countries and DACH}

As another example, an assessment of the DRVs used by different groups of countries in Europe shows diversity in approaches. The five Scandinavian countries (Denmark, Finland, Iceland, Norway and Sweden) have for many years jointly published the NNR $[7,8]$. The three German-speaking countries, Austria, Germany and Switzerland (DACH) [9], also jointly publish nutrient recommendations $[9,10]$. The NNR and DACH recommendations are based on the present nutrition situation in the relevant countries.

The 4 th edition of the NNR $[7,8]$ gives the proportions between energy-yielding nutrients, recommended daily intakes of vitamins and minerals, and reference values for energy intakes in different age and sex groups. Recommendations are also given for dietary fiber, salt and alcohol. Food-based guidelines are also included, as well as recommendations on physical activity. For infants the importance of breastfeeding is emphasized. The development of NNR was supported by comments and contributions from a large number of nutrition experts, national agencies and institutes in the Nordic countries helping to construct recommendations as evidence-based as possible [8].

In 2000 the nutrition societies of Germany, Austria and Switzerland (DACH) $[9,10]$ published reference values for nutrient intake based partly on earlier recommendations published in Germany. The nutrient data and energy values are similar to those of equivalent scientific bodies in other countries and those of FAO/WHO. DACH values consist of part I 'Nutritive aspects of nutrients' and part II 'Preventive aspects of nutrients and food components'. In part I special attention is given to the requirement of nutrients and nutrient density. Part II aims at preventing nutrition-related diseases. Here it is emphasized that excessive intake of energy, fat, and alcohol should be avoided. Also the beneficial effects of special nutrients like folic acid against neural tube defects or vitamin $\mathrm{K}$ against osteoporosis are mentioned. Furthermore it is underlined that the DACH reference values have taken energy density into account; this is specifically important for the regulation of food intake and energy balance [9]. 
The DACH reference values have been translated into English, French, Hungarian and Slovenian, and they are also used by Hungary and Slovenia. The next edition will be prepared in collaboration with colleagues from Hungary, Slovenia and Czechia [9]. As stated earlier, the terminologies used in the $\mathrm{DACH}$ report are as follows.

\section{Energy Requirement and Recommended Intake}

Energy requirement is the amount of food energy needed to balance energy expenditure to maintain body size, body composition, and the level of necessary and desirable physical activity consistent with long-term good health. The recommended level of dietary energy intake for a population group is the mean energy requirement of the healthy, well-nourished individuals who constitute that group $[2,12]$. Human energy requirements are estimated from measurements of energy expenditure of normal weight people plus the additional energy needs for growth, pregnancy and lactation. Recommendations for dietary energy intake from food must satisfy these requirements for the attainment of optimal health, physiological function and wellbeing. An adequate, healthy diet must satisfy human needs for energy and all essential nutrients. The energy is supplied by carbohydrates, proteins, fats and alcohol in diets $[2,12]$. Energy requirements are partly calculated based on an equation published by WHO in 1985 for the basal metabolic rate [12]. Adjustments are made to the resting energy expenditure to take account of the different energy requirements at varying levels of activity according to age. The $\mathrm{DACH}$ reference values have used the double-labelled water technique to measure the average total energy expenditure and predictive formulae to calculate the average basal metabolic rate [12]. DACH reference values also make allowances for different levels of physical activity [9].

The NNR define energy requirement in adults as the energy intake needed to cover energy expenditure in individuals, along with body weight and composition, and physical activity compatible with good health $[7,8]$. In NNR 2004 reference values for energy requirements are based on data using double-labelled water in infants and children up to 5 years. The reference values for age groups of children and adolescents are based on total energy expenditure using estimations of the basal metabolic rate and the physical activity level. Three physical activity levels are given: light (1.45-1.60), moderate (1.65-1.80), and heavy $(1.90-2.05)[7,8]$.

The various recommendations seem thus to be based on the same or very similar methodologies that should give the same values for the same age groups.

Harmonizing Energy and Nutrient Recommendations

\section{Macronutrients}

A comparison of the different recommendations for macronutrients in some European countries, WHO/ FAO, and USA and Canada are presented in table 1. Most of the recommendations are the same, or in a similar range. The recommendations for protein, however, are expressed differently, either as grams per day or grams per kilogram per day, and usually without an indication of a representative weight at each age to allow conversion of one to the other $[15,16]$. The Joint FAO/WHO/UNU Expert Consultation of 1985 [12] defined the protein requirement of an individual as 'the lowest level of dietary protein intake that will balance the losses of nitrogen from the body in persons maintaining energy balance at modest levels of physical activity' [12]. This Expert Consultation sets the average daily protein requirement for adults to $0.75 \mathrm{~g}$ of good quality protein/ $\mathrm{kg}$ body weight/ day based on the estimated average requirement of 0.6 g/day, with $2 \mathrm{SD}(2 \times 12.5 \%)$ to allow for individual variability. For adults the NNR $[5,6]$ is $10-20$ E\% (total energy intake), also during pregnancy and for lactating women, $7-15 \mathrm{E} \%$ for infants $6-11$ months $(1.1 \mathrm{~g} / \mathrm{kg}$ body weight), $10-15 \mathrm{E} \%$ for $12-23$ months $(1.0 \mathrm{~g} / \mathrm{kg}$ body weight) and $0.9 \mathrm{~g} / \mathrm{kg}$ body weight for 2 - to 17 -year-olds. Protein requirements of the growing organism are defined by the need for maintenance and growth. The values of the protein reference intake are based on factorial methods and on the assumption that children have a similar mean maintenance requirement to adults when expressed relative to body weight. The Joint FAO/WHO Expert Consultation of 1991 [17] proposed a protein digestibility-corrected amino acid score for all children over 2 years of age and to adulthood. It has been recommended to assess how dietary proteins can meet requirements for essential amino acid by comparing their amino acid pattern (milligrams of amino acid per gram of dietary protein) with the amino acid requirement pattern (milligrams of amino acid per gram of recommended protein intake). The $\mathrm{DACH}$ recommendations for protein intake are $8-10 \mathrm{E} \%$ or $0.8 \mathrm{~g} / \mathrm{kg} /$ day for healthy adults $[9,10]$.

The human body can synthesize both saturated and monounsaturated fatty acids from acetate, whereas polyunsaturated fatty acids (both in n-6 linoleic acid and n-3 $\alpha$-linolenic acid series) are required from the diet, they are therefore called essential fatty acids. These essential fatty acids are important for various cell membrane functions such as fluidity, permeability, activity of membranebound enzymes and receptors and signal transduction. Linoleic and $\alpha$-linolenic acids can be elongated and desaturated in the body, transforming into biologically ac-

Ann Nutr Metab 2007:51:108-114 
Table 1. Comparison of the reference values and participation of macronutrients in different recommendations

\begin{tabular}{|c|c|c|c|c|c|}
\hline Nutrient & NNR 2004 & DACH 2000 & $\begin{array}{l}\text { WHO/FAO } \\
2003\end{array}$ & $\begin{array}{l}\text { Euro diet } \\
2000\end{array}$ & $\begin{array}{l}\text { USA/Canada } 2002 \\
\text { AMDR }\end{array}$ \\
\hline Total fat, \%E & $30(25-35)$ & 30 & $15-30$ & $<30$ & $20-35$ \\
\hline SFA & $\leq 10$ & 10 & $<10$ & $<10$ & as low as possible \\
\hline PUFA & $5(-10)$ & $7-10$ & $6-10$ & - & - \\
\hline n-6 PUFA & $4(-9)$ & 2.5 & $5-8$ & $4-8$ & 5-10 linoleic \\
\hline n-3 PUFA & 1 & 0.5 & $1-2$ & 2 linolenic & $0.6-1.2$ \\
\hline Trans-fatty acids & incl. SFAs & 1 & $<1$ & $<2$ & as low as possible \\
\hline MUFA & $10-15$ & by difference & by difference & & - \\
\hline Total carbohydrate, E\% & $55(50-60)$ & 50 & $55-75$ & $>55$ & $45-65$ \\
\hline Free sugars, E\% & $<10$ & 30 & $<10$ & & $<25$ \\
\hline Dietary fiber, g/day & 25-35 (3 g/MJ) & $(12.5 \mathrm{~g} / 1,000 \mathrm{kcal})$ & & & $25-38(14 \mathrm{~g} / 1,000 \mathrm{kcal})$ \\
\hline Protein, E\% & $15(10-20)$ & $8-10$ & $10-15$ & - & $10-35$ \\
\hline Cholesterol, mg/day & & 300 & $<300$ & & as low as possible \\
\hline Sodium chloride (sodium), g/day & $5-6(2.3-2.7)$ & & $<5(2)$ & & \\
\hline
\end{tabular}

$\mathrm{AMDR}=$ Acceptable macronutrient distribution; $\mathrm{SFA}=$ saturated fatty acids; $\mathrm{PUFA}=$ polyunsaturated fatty acids; $\mathrm{MUFA}=$ monounsaturated fatty acids.

tive substances like prostaglandins, prostacyclins and leukotrienes. These substances participate in the regulation of blood pressure, renal function, blood coagulation, inflammatory and immunological reactions and other functions [7]. The DACH Reference Guiding Values for total fat intake of adults (not more than $30 \%$ of the energy intake) are related to light work, heavy muscle work (not more than $35 \%$ of energy intake) and extremely heavy work (not more than 40\%). Saturated fatty acids should not exceed $10 \%$ of energy. Polyunsaturated fatty acids should provide about $7 \%$ and up to $10 \%$ if saturated fatty acids provide more than $10 \%$ of energy. Monounsaturated fatty acids should constitute the rest. Trans-fatty acids should contribute not more than $1 \mathrm{E} \%$. The ratio of $\mathrm{n}-6$ linoleic acid to $\mathrm{n}-3 \alpha$-linolenic acid should be about 5:1 $[9,10]$. These fatty acids compete for metabolic enzymes and it is therefore important to maintain a balance between them [7]. The NNR recommends limiting the intake of saturated plus trans-fatty acids to about 10 $\mathrm{E} \%$ and the total fat intake to $30 \mathrm{E} \%(25-30 \%)[7,8]$.

The recommendations for carbohydrate intake are from $50 \mathrm{E} \%$ in the $\mathrm{DACH}$ reference values $[9,10]$ to 55 $\mathrm{E} \%$ (50-60 E\%) in NNR recommendations $[7,8], 55-75$ $\mathrm{E} \%$ in $\mathrm{WHO} / \mathrm{FAO}[12]$ and $45-65 \mathrm{E} \%$ in USA/Canada recommendations [18] as presented in table 1.

\section{Physical Activity}

Detailed recommendations on daily physical activity are included in the 4 th edition of the NNR. For children and adolescents a minimum of 60 min of physical activity are recommended every day. Activities can be divided into shorter intervals and should be as diverse as possible to provide opportunities for developing all aspects of physical fitness. Regular physical activity is necessary for the development of cardiorespiratory endurance, greater bone density, muscle strength, flexibility and motor skills. For adults, $30 \mathrm{~min}$ of daily physical activity of moderate and/or vigorous intensity is recommended. For prevention of weight gain more physical activity might be needed (about 60 min daily). This should be in addition to normal daily activity. Adequate physical activity contributes to the prevention of lifestyle-related diseases such as cardiovascular diseases, hypertension, type- 2 diabetes, osteoporosis and certain types of cancer. Physical activity also plays a vital role in the prevention of overweight [7]. In the DACH reference values a physical activity level of at least 1.75 is considered necessary to reduce the risk of lifestyle-related diseases [9].

\section{Special Recommendations for Infants and Children}

Exclusive breastfeeding is the preferable source of nutrition for infants up to 6 months; no recommendations for single nutrients are therefore given for that age group. From 4 weeks of age infants should receive $10 \mu \mathrm{g}$ vitamin $\mathrm{D}$ as a supplement. For children aged 6-23 months, the energy intake from fat should decline from the high level during the first year (35-45 E\%) and gradually reach the recommended level for older children and adults $(\sim 30$ 
E\%). During the same period, protein intake should increase from about $5 \mathrm{E} \%$ (the level in breast milk) to the recommended intake for older children and adults (10-20 $\mathrm{E} \%)$. The intake of appropriate amounts of dietary fiber from a variety of foods is important for children. From school age the intake should gradually increase to reach the recommended level during adolescence. Physical activity is especially important for children because the prevalence of overweight and obesity have steadily been increasing [7]. DACH reference values for infants and children are generally in a comparable range, but here recommendations for single nutrients are also given for infants up to 6 months [9].

\section{Special Recommendations from NNR for the Elderly}

Recommendations for the elderly are often extrapolated from data for younger adults, as knowledge is still limited in spite of growing scientific evidence. The recommendations are mostly the same or similar to recommendations for other adults. Energy intake often decreases with age; therefore higher nutrient density can be favorable. Elderly people with little or no sun exposure should receive a supplement of $10 \mu \mathrm{g}$ vitamin D3 daily in addition to dietary intake. If energy intake and energy expenditure is low ( $<6.5 \mathrm{MJ}$ /day), a multivitamin tablet is more relevant than vitamin $\mathrm{D}$ alone [7]. In the $\mathrm{DACH}$ an increased nutrient density for several nutrients is recommended for the elderly, especially vitamin $\mathrm{D}$, for which a doubling of the intake is recommended [9].

\section{Conclusions}

There are wide disparities across Europe in current dietary reference values and recommendations. Some European countries have published their own guidelines or have accepted those suggested by others. Comparison of the existing recommendations for children is difficult because they use different age groups in childhood, and some of the countries give different reference intakes for males and females from the 2nd year of age onwards. Furthermore, others give the same reference intake for both sexes in early childhood but separate them in later childhood and adolescence to take account of the different requirements of the sexes at various ages (increasing for males and women who have increased needs of various nutrients during pregnancy). Another challenge is the variation in the use of terminology and the confusion this creates about whether the reference values converge, or whether the scientific evidence points to real differences in requirements between populations/ groups.

Generally, such divergences point to the need for harmonization in energy and nutrient reference values across Europe. Harmonization would simplify nutritional policy-making, delivery of diet and health guidance, improve public understanding and minimize barriers-to-trade across national boundaries with respect to food-labeling. However, this is not an inconsiderable task and there are many hurdles to overcome, not least due to the geographical, dietary and lifestyle differences that exist across Europe.

What then are the harmonization needs? Briefly they can be summed up as follows:

1 Harmonize terminology in reference values;

2 Standardize target values for assessing the requirements for a nutrient;

3 Standardize age groups and pubertal milestones;

4 Harmonize the reference values in Europe, when possible, and explain acceptable differences;

5 Review the scientific evidence about requirements for macronutrients energy and physical activity with a view to setting harmonized reference values. Consider the scientific evidence for local variation in dietary requirements (e.g. in vitamin $\mathrm{D}$, iron, zinc and iodine) to establish where different reference values will continue to be required within Europe.

\section{Acknowledgement}

This work was supported by grant No. 145071, Ministry of Science and Environment Protection, Republic of Serbia. 


\section{References}

1 Aggett PJ, Bresson J, Haschke F, et al: Recommended Dietary Allowances (RDAs), Recommended Intakes (RDIs), Recommended Nutrient Intakes (PRIs) are not 'recommended intakes'. J Pediatr Gastroenterol Nutr 1997;25:236-241.

2 FAO/WHO/UNU: Human Energy Requirements. Report of a Joint Expert Consultation Rome, 17-24 October 2001. FAO Food and Nutrition Technical Report Series, 2001.

3 FENS (2005): http://www.fensweb.org/show article.php menu $=1 \&$ article $=2 \&$ channel $=1$ (as of April 7, 2006).

4 Dietary Reference Values for Food Energy and Nutrients for the United Kingdom, 10th impression (with revised section on fluoride). London, Stationery Office, Department of Health, 1991.

5 Prentice A, Branca F, Decsi T, Michaelsen KF, Fletcher RJ, Guesry P, Manz F, Vidailhet M, Pannemans D, Samartin S: Energy and nutrient dietary reference values for children in Europe: methodological approaches and current nutritional recommendations. Br J Nutr 2004;92(suppl 2):S83-S146.

6 Prentice A: An overview of nutrient reference values across Europe, power point presentation from the FENS workshop 'Harmonization of the nutrient requirements'. IUNS 18th Int Congr Nutr, Sept 2005, Durban, South Africa.
7 Nordic Nutrition Recommendations 2004 Integrating Nutrition and Physical Activity. NORD 2004. Copenhagen, Nordic Council of Ministries, 2004.

8 Becker B, Lyhne N, Pedersen AN, Aro A, Fogelholm M, Thorsdottir I, Alexander J, Andersen SA, Meltzer HM, Pedersen JI: Nordic nutrition recommendations 2004 - integrating nutrition and physical activity (abstract). 18th Int Congr Nutr, Sept 2005, Durban South Africa. Nutrition Safari for Innovative Solutions. Ann Nutr Metabol 2005(suppl 49):85.

9 German Nutrition Society, Austrian Nutrition Society, Swiss Society for Nutrition Research, Swiss Nutrition Association: Reference Values for Nutrient Intake (D-A-CH), ed 1. Frankfurt am Main, Umschau/Braus, 2000.

10 Wolfram G, Elmadfa I, Erbersdobler H, Stehle P, Walter P: DACH - reference values. A model for reference values in central Europe (abstract). 18th Int Congr Nutr, Sept 2005, Durban, South Africa. Nutrition Safari for Innovative Solutions. Ann Nutr Metab 2005(suppl 49):85.

11 WHO/FAO: Human Vitamin and Mineral Requirements. Report of a Joint FAO/WHO Expert Consultation, Bangkok. WHO/FAO, Rome, 2002.
12 WHO: Energy and protein requirements. Report of a joint FAO/WHO/UNU Expert Consultation. World Health Organ Tech Rep Ser 1985;724:1-206.

13 WHO/FAO: Diet, nutrition and the prevention of chronic diseases. World Health Organ Tech Rep Ser 2003;916:i-viii, 1-149, backcover.

14 Scientific Committee on Food of the European community: Proposed nutrient and energy intakes for the European Community. Nutr Rev 1993;51:209-212.

15 Scrimshaw NS: Human protein requirements: a brief update. http://www.unu.edu/ unupress/food/8F173e/8F173E02.htm (as of April 8, 2006).

16 Jackson AA: Human protein requirement: policy issue. Proc Nutr Soc 2001;60:7-11.

17 Food and Agriculture Organization (FAO/ World Health Organization): Protein Quality Evaluation in Human Diets. FAO Food and Nutrition Paper 51. Rome, FAO, 1991.

18 IM: Dietary Reference Intakes for Energy, Carbohydrate, Fiber, Fat, Fatty Acids, Cholesterol, Protein, Amino Acids. Washington, Institute of Medicine, 2002. www.nap.edu/ catalog/10490.html (as of April 7, 2006). 